\title{
SISTEM INFORMASI PEMBAYARAN SPP PADA SMK SWASTA TELADAN TANAH JAWA MENGGUNAKAN VB.NET
}

\author{
Heru Sugara1', Erwin Sirait ${ }^{2}$, M. Ali Hanafiah ${ }^{3)}$, Nancy Florida Siagian ${ }^{4)}$ \\ ${ }^{1}$ Sekretari, Politeknik Bisnis indonesia \\ email: thesugara77@gmail.com \\ ${ }^{2,3}$ Teknik Komputer, Politeknik Bisnis Indonesia \\ email: e7rait@yahoo.com, ikh.alie84@gmail.com \\ ${ }^{4}$ Keuangan dan Perbankan, Politeknik Bisnis Indonesia \\ email: siagiannancyflorida@gmail.com
}

\begin{abstract}
The purpose of this study was to solve the problem of recording and processing data on tuition payments which were still done manually in schools at Teladan Tanah Jawa Private Vocational High Schools. This problem was solved by designing a tuition payment accounting information system using $V b . N e t$ which aims to simplify and speed up the work of processing data on tuition payments at the Teladan Tanah Jawa private vocational school. The research method used in this research is observation, interview, sampling, and literature study. Analysis tools used are Data Flow Diagrams (DFD), Entity Relationship Diagrams (ERD) and relationships between tables (RAT). The result of designing this system is an information system that is able to facilitate the work of the school administration to find student data, process arrears data, recapitulate data on daily tuition payments and make reports on tuition payments quickly and efficiently.
\end{abstract}

Keywords: Tuition Payment, Accounting Information System, Design, Arrears, VB.Net.

\section{PENDAHULUAN}

Untuk mempercepat proses kerja di suatu lembaga atau yayasan dibutuhkan suatu sistem informasi [1]-[8]. Sistem informasi dibutuhkan untuk mempercepat proses kerja, mengolah datadata transaksi, mengurangi biaya dan untuk mendapatkan informasi yang lebih cepat dan akurat [9]-[15].

Salah satu sistem informasi adalah sistem informasi akuntansi. Sistem informasi akuntansi dalam suatu organisasi atau perusahaan sangat dibutuhkan sebagai alat untuk mengidentifikasi, mengukur, mencatat, dan menyimpan informasi keuangan. Dengan adanya sistem informasi akuntansi tersebut sebuah lembaga atau yayasan dalam menghasilkan laporan keuangan akan lebih efisien dan lebih akurat [16], [17].

Yayasan pendidikan Teladan yang beralamat di jalan besar Balimbingan Tanah Jawa merupakan yayasan yang bergerak dalam bidang pendidikan. Yayasan Pendidikan Teladan Tanah Jawa merupakan sekolah yang didirikan dengan modal sendiri yaitu dari pemilik yayasan.

Yayasan pendidikan Teladan pada saat ini belum menggunakan sistem informasi dalam pembayaran SPP (Sumbangan Pembinaan Pendidikan). Mengingat yayasan pendidikan Teladan memiliki banyak siswa dan pencatatan pembayaran SPP masih menggunakan sistem manual, yakni pencatatan masih menggunakan buku catatan harian pembayaran SPP atau buku besar, maka proses pencatatan dan pembuatan laporan uang sekolah tersebut masih sangat lambat dan juga sering mengalami kesalahan pencatatan atau keliru dalam perhitungan SPP setiap bulannya. Permasalahan lain yang sering dikeluhkan adalah sulitnya mengumpulkan data pembayaran SPP yang terpisah-pisah di beberapa buku keuangan.

Untuk mengatasi hal tersebut, dirancang sebuah sistem informasi akuntansi pembayaran SPP dengan menggunakan Vb.Net. yang dapat mempermudah pihak sekolah dalam pelayanan administrasi pembayaran SPP sehingga pekerjaan 
pencatatan uang sekolah dapat dilakukan dengan cepat dan efektif sehingga mengurangi kesalahan pencatatan pembayaran. Selain itu, Sistem ini juga mempermudah pihak administrasi dalam mencari data siswa, mengolah data tunggakan, data pembayaran harian SPP dan laporan pembayaran SPP.

\section{METODE PENELITIAN}

\section{Perancangan Sistem}

Perancangan sistem diawali dengan membuat DFD (Data Flow Diagram) berupa diagram yang menggambarkan arus dari data sistem, yang penggunaanya sangat membantu untuk memahami sistem secara logika, terstruktur dan jelas.

\section{Diagram Konteks}

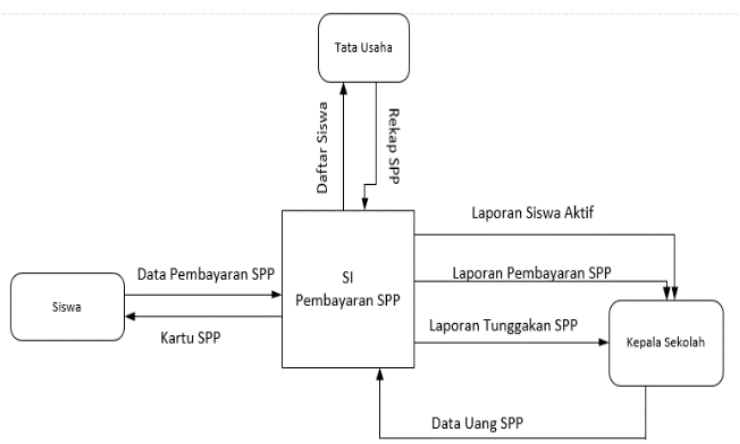

Gambar 1. Gambar Diagram Konteks

\section{DFD Level 1}

$D F D$ level 1 terdiri dari 3 proses yaitu proses cek data siswa, proses pembayaran SPP dan proses pembuatan laporan.

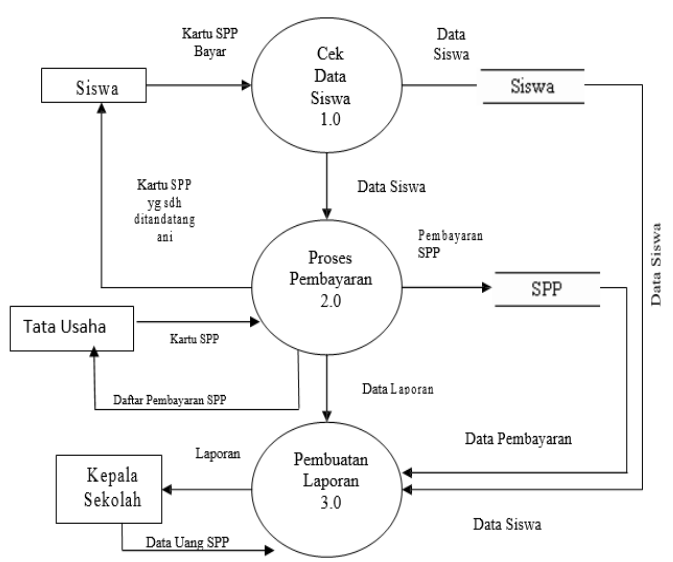

Gambar 2. Gambar DFD Level 1

\section{Rancangan Masukan}

Rancangan masukan merupakan gambaran secara umum tentang visualisasi dari aplikasi yang akan dibuat, antara lain:

a) Desain input login

Desain input form login akan digunakan sebagai interface untuk pengguna apabila akan masuk ke seluruh fungsi menu dengan melakukan otorisasi melalui user dan password. Desain login dapat dilihat pada Gambar 3.

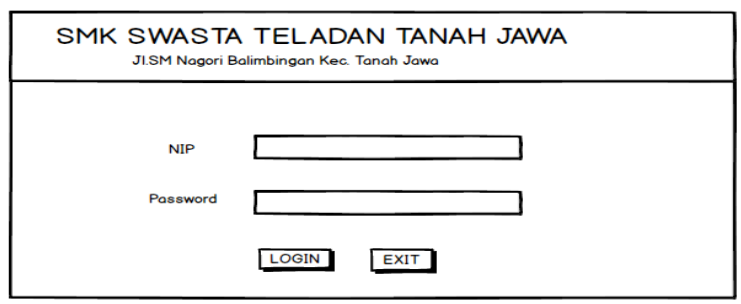

Gambar 3. Desain Form Login

b) Desain menu utama

Desain menu utama digunakan agar user dapat mengakses form-form yang diinginkan. Menu yang ada sesuai dengan hak akses user yang telah di tentukan pada saat login. desain menu utama dapat dilihat pada Gambar 4.

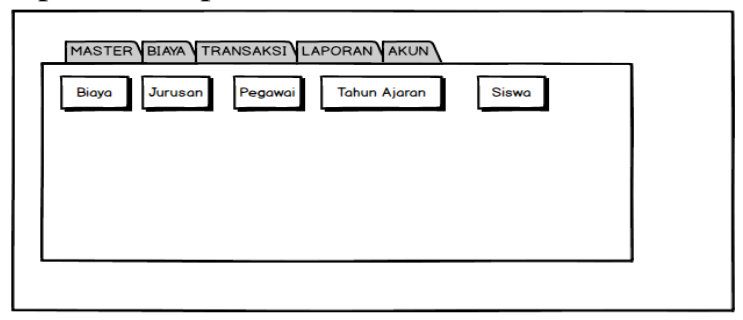

Gambar 4. Desain Form Menu Utama

c) Desain form siswa

Form master siswa merupakan form yang digunakan untuk maintenance data siswa. Desain form siswa dapat dilihat pada Gambar 5.

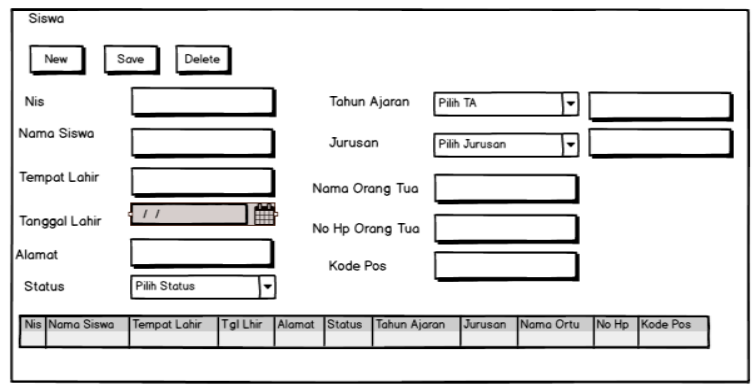

Gambar 5. Desain Form Siswa 


\section{d) Desain form Biaya}

Form master biaya merupakan form yang digunakan untuk maintenance master data biaya. Desain master biaya dapat dilihat pada Gambar 6.

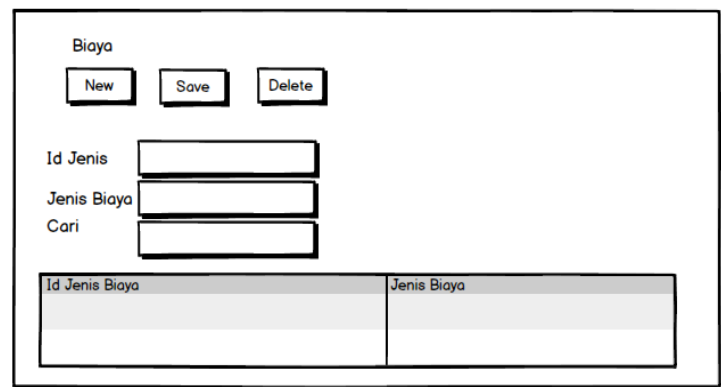

Gambar 6. Desain Form Biaya

e) Desain form pegawai

Form master admin merupakan form yang digunakan untuk maintenance master data admin yang terdiri dari NIP, nama, jabatan, password, desain master admin dapat dilihat pada gambar 7 .

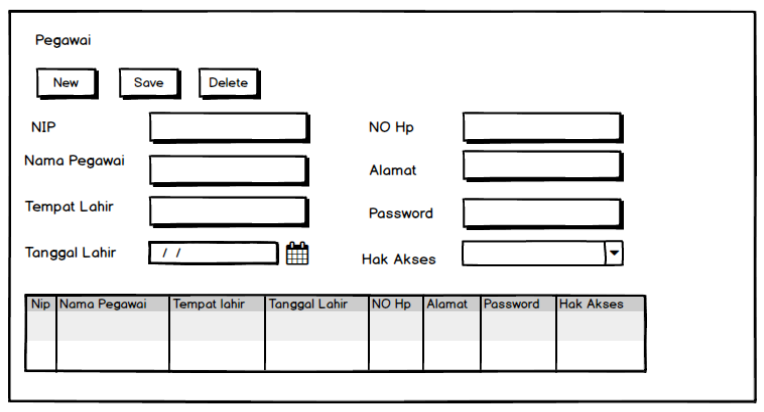

Gambar 7. Desain Form Pegawai

f) Desain transaksi pembayaran

Form transaksi pembayaran merupakan form yang digunakan untuk menyimpan data transaksi yang telah dibayar oleh siswa. Desain Transaksi pembayaran dapat dilihat pada Gambar 8 .

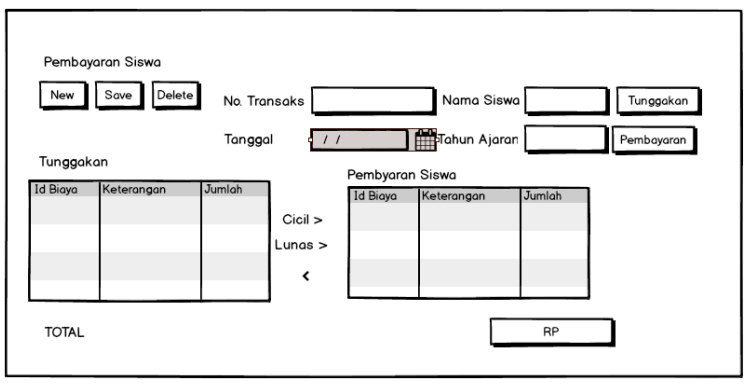

Gambar 8. Desain Form Pembayaran

\section{Entity Relation Diagram Basis Data}

Bentuk dari Entity Relation Diagram dari basis data Sistem Infromasi Pembayaran SPP pada SMK Swasta Teladan Tanah Jawa adalah seperti pada gambar 9 .

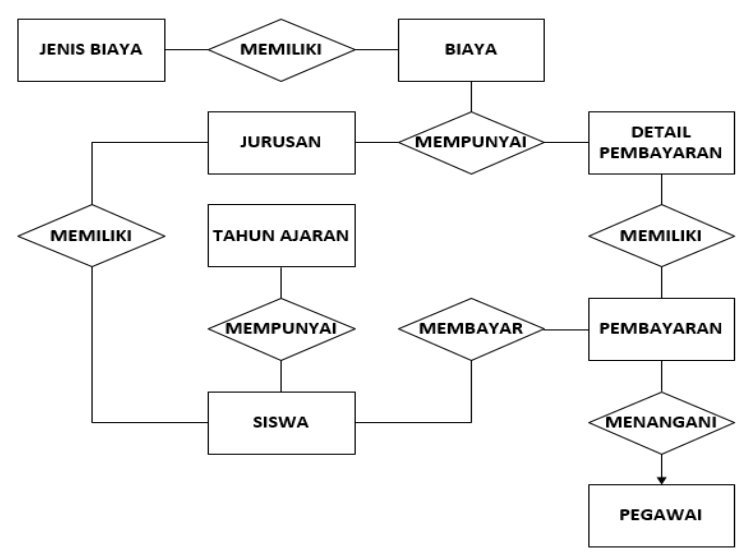

Gambar 9. Entity Relation Diagram

\section{HASIL DAN PEMBAHASAN}

Hasil implementasi dari perancangan penelitian ini berupa sebuah Aplikasi Pencatatan Laporan Penjualan Kita-Kita.Net.

\section{Form Login}

Sebelum masuk ke menu utama hal yang pertama kali dilakukan adalah login. Pada form login ini, user harus menginput Username dan Password sesuai yang telah dibuat oleh admin. Berikut tampilan dari form login.

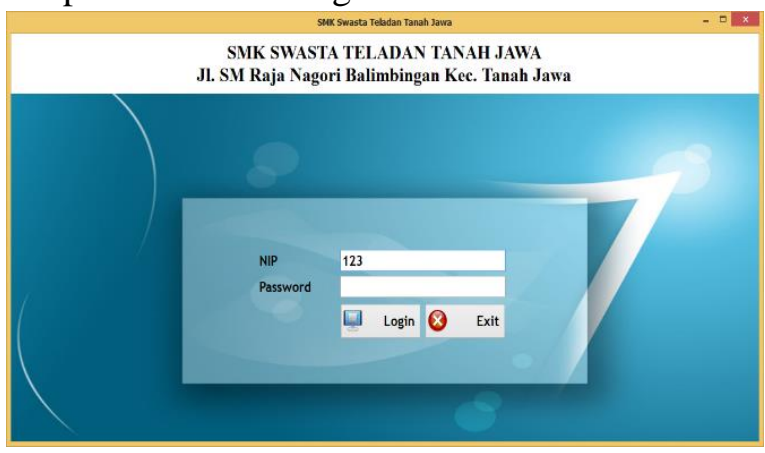

Gambar 10. Tampilan Halaman Login

\section{Halaman Menu Utama}

Tampilan ini merupakan tampilan awal pada saat sistem dijalankan dan merupakan suatu tampilan untuk menampilkan menu-menu lainnya yang ada di dalam sistem informasi ini. Tampilan 
menu utama terdiri dari master, biaya, transaksi, laporan dan akun. Tampilan Menu utama terlihat pada gambar 11 .

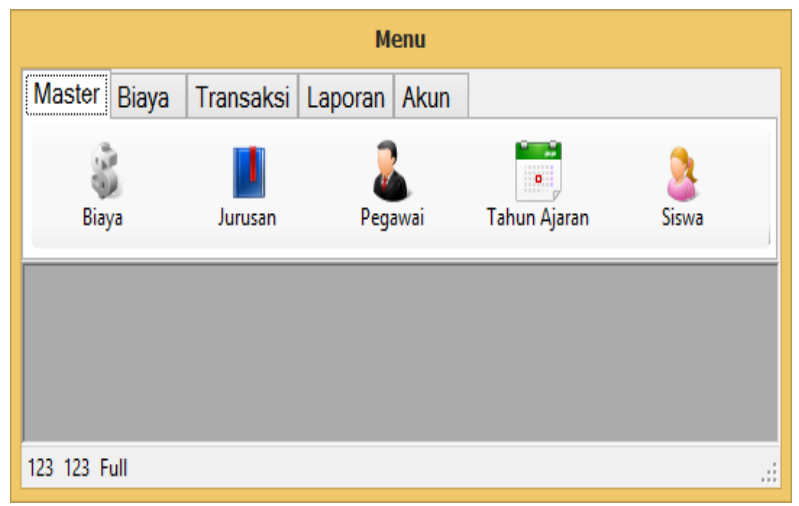

Gambar 11. Tampilan Halaman Menu utama

\section{Form Siswa}

Form Siswa digunakan untuk menginput dan mengolah datasiswa. Tampilan data siswa dapat dilakukan dengan memililih menu master kemudian pilih siswa. Proses untuk menambah data siswa dengan memilih menu tambah. Pencarian data siswa dapat di filter dengan pencarian kelas. Form untuk data siswa ada pada gambar 12.

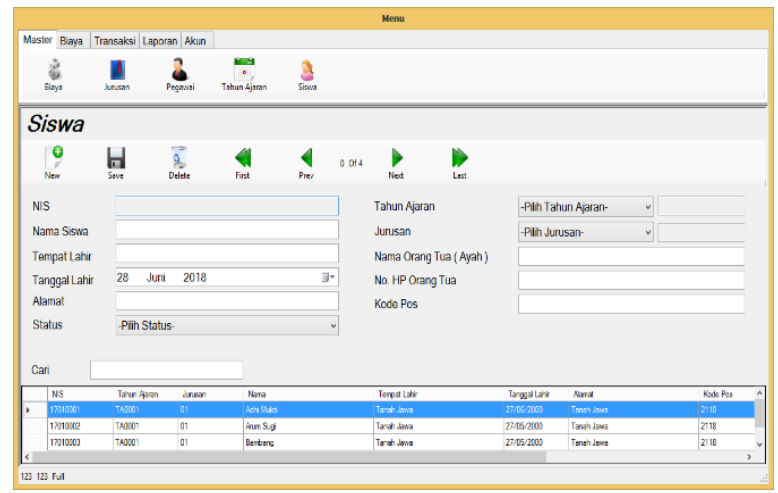

Gambar 12. Tampilan Form Siswa

\section{Form Jurusan}

Form jurusan digunakan untuk menginput jurusan siswa. Tampilan data jurusan dapat dilakukan dengan memilih menu master kemudian jurusan. Halaman jurusan terdapat aksi untuk mengedit dan menghapus jurusan.Pada SMK Swasta Teladan Tanah Jawa terdapat 4 jurusan. Data jurusan ada pada gambar 13.

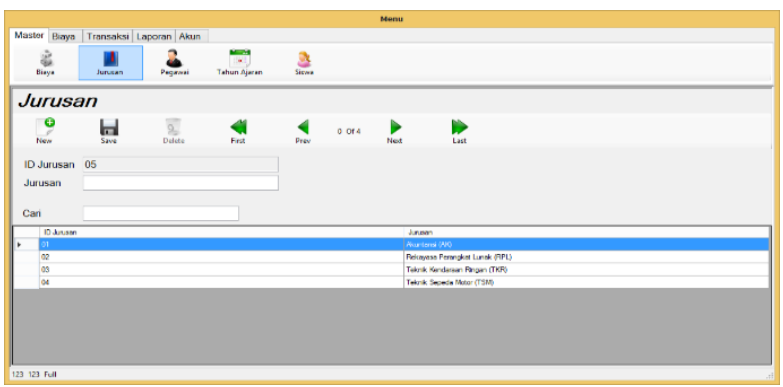

Gambar 13. Tampilan Form Jurusan

\section{Form Tahun Ajaran}

Form tahun ajaran digunakan untuk menginput dan mengolah data Tahun Ajaran. Tampilan data Tahun Ajaran dapat dilakukan dengan memilih menu master kemudian Tahun Ajaran. Tampilan data tahun ajaran ada pada gambar 14 .

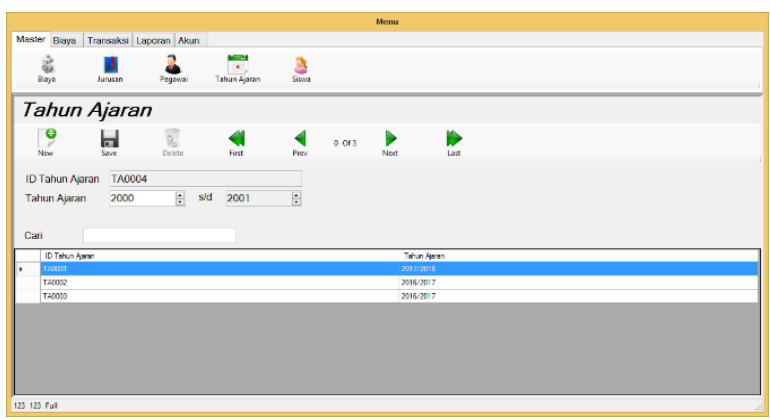

Gambar 14. Tampilan Form Tahun Ajaran

\section{Form biaya SPP}

Form biaya SPP digunakan untuk menginput jumlah biaya SPP per bulan setiap jurusan. Data tarif SPP dapat dilakukan dengan memilih menu biaya kemudian klik biaya SPP. Pada halaman biaya SPP terdapat menu new yang digunakan untuk menambahkan biaya SPP yang sesuai dengan ketentuan sekolah. Form biaya SPP dapat dilihat pada gambar 15 .

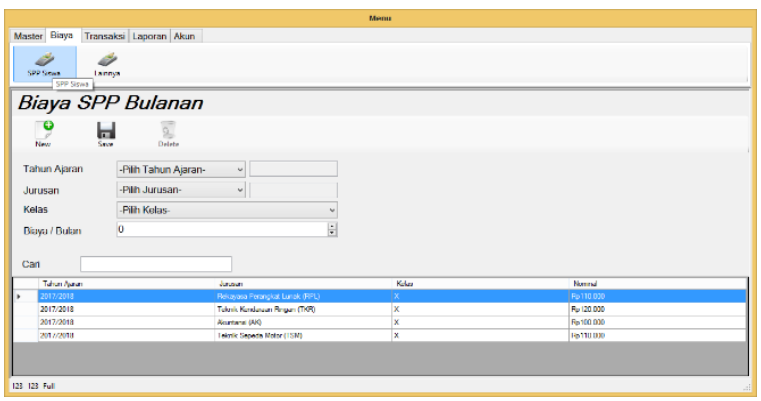

Gambar 15. Tampilan Form biaya SPP 


\section{Form data tunggakan SPP dan pembayaran SPP}

Form data tunggakan SPP dan pembayaran SPP digunakan untuk melihat data tunggakan SPP siswa. Selanjutnya dari tunggakan form ini bisa langsung melakukan transaksi pembayaran SPP siswa. Proses transaksi pembayaran SPP dapat dilakukan dengan memilih menu Transaksi. Tampilan Form pembayaran SPP seperti pada gambar 16.

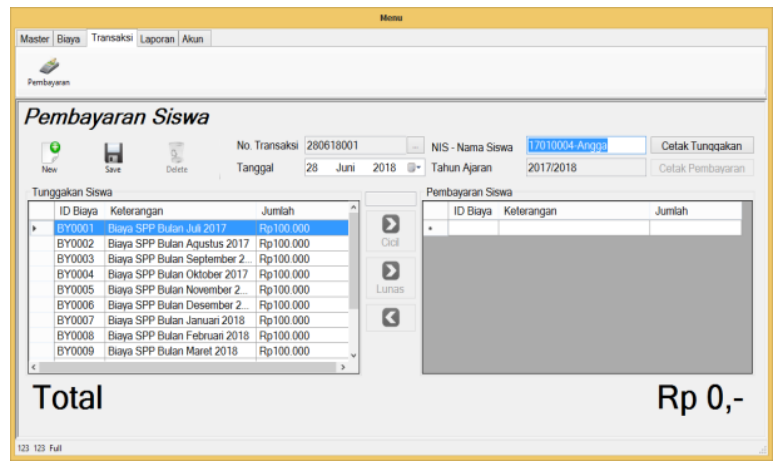

Gambar 16. Tampilan Form pembayaran SPP

\section{Laporan data biaya}

Laporan data biaya digunakan untuk menampilkan data biaya SPP per bulan.

\begin{tabular}{|c|c|c|c|c|c|c|}
\hline \multicolumn{7}{|c|}{$\begin{array}{l}\text { SMK SWASTA TELADAN TANAH JAWA } \\
\text { JIn. SM Raja Nagori Balimbingan Kec. Tanah Jawa }\end{array}$} \\
\hline ID Biaya & Jenis Biaya & TA. & Jurusan & Kelas & Keterangan & Jumlah \\
\hline BY0001 & & & & $x$ & Biava SPP Bulan Juli 2017 & Rp100.000 \\
\hline BYO002 & SPP & $2017 / 2018$ & Akuntansi (AK) & $\hat{x}$ & Biaya SPP Bulan Agustus 2017 & Rp100.000 \\
\hline BYO003 & SPP & $2017 / 2018$ & Akuntansi (AK) & $\hat{x}$ & Biaya SPP Bulan September 2017 & $\operatorname{Rp} 100.000$ \\
\hline BY0004 & SPP & $2017 / 2018$ & Akuntansi (AK) & $\hat{x}$ & Biaya SPP Bulan Oktober 2017 & Rp 100.000 \\
\hline BY0005 & SPP & 2017/2018 & Akuntansi (AK) & $x$ & Biava SPP Bulan November 2017 & Rp 100.000 \\
\hline BYO006 & SPP & $2017 / 2018$ & Akuntansi (AK) & $x$ & Biaya SPP Bulan Desember 2017 & Rp100.000 \\
\hline BY0007 & SPP & 2017/2018 & Akuntansi (AK) & $x$ & Biaya SPP Bulan Januari 2018 & Rp 100.000 \\
\hline BYOOOB & SPP & 2017/2018 & Akuntansi (AK) & $\mathrm{x}$ & Biaya SPP Bulan Februari 2018 & Rp100.000 \\
\hline BYOO09 & SPP & 2017/2018 & Akuntansi (AK) & $\mathrm{x}$ & Biaya SPP Bulan Maret 2018 & Rp 100.000 \\
\hline BYO010 & spp & $2017 / 2018$ & Akuntansi (AK) & $x$ & Biaya SPP Bulan April 2018 & Ro 100000 \\
\hline BY0011 & SPP & $2017 / 2018$ & Akuntansi (AK) & $\mathrm{x}$ & Biava SPP Bulan Mei 2018 & Rp 100000 \\
\hline BYo012 & spp & 20172018 & Akuntansi (AK) & $x$ & Biava SPP Bulan Juni 2018 & Ro100.000 \\
\hline
\end{tabular}

Gambar 17. Tampilan laporan jenis biaya

\section{Form laporan data pembayaran}

Laporan data pembayaran digunakan untuk menampilkan laporan siswa yang telah membayar SPP setiap harinya. Tampilan Laporan pembayaran SPP dapat dilakukan dengan memilih menu Laporan kemudian Laporan Pembayaran SPP. Tampilan laporan pembayaran SPP ada pada gambar 18 .

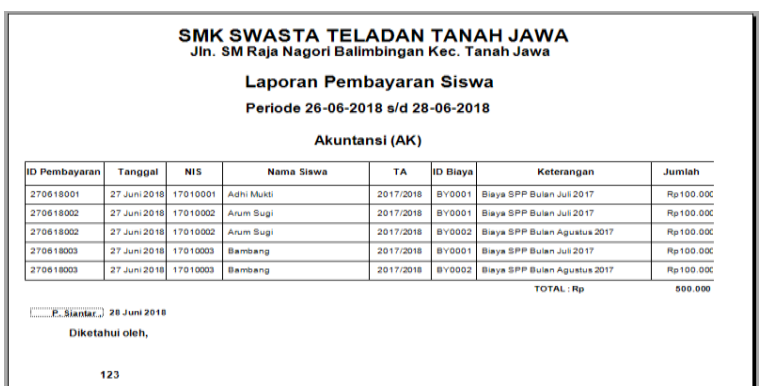

Gambar 18. Tampilan laporan pembayaran

\section{KESIMPULAN}

Setelah melakukan implementasi Sistem Informasi Pembayaran SPP Pada SMK Swasta Teladan Tanah Jawa Menggunakan VB.NET maka dapat diambil kesimpulan sebagai berikut :

1. Sistem informasi pembayaran ini sangat membantu menangani atau mempermudah pembayaran SPP untuk SMK .

2. Sistem informasi pembayaran SPP di SMK Swasta Teladan Tanah Jawa dapat mengefisiensikan waktu dan pekerjaan dalam menangani atau mempermudah pembayaran SPP untuk SMK .

3. Melalui sistem informasi pembayaran SPP ini, pencarian data tunggakan uang sekolah dan juga pembuatan laporan pembayaran uang sekolah dapat lebih mudah untuk dilakukan.

\section{REFERENSI}

[1] V. Sihombing and G. J. Yanris, "PENERAPAN APLIKASI DALAM MENGOLAH ASET DESA (STUDI KASUS: KEPENGHULUAN SRI KAYANGAN)," J. Mantik Penusa, vol. 4, no. 1, pp. 12-15, 2020.

[2] J. Simatupang, "Perancangan Sistem Inventori Barang pada Toko Nichos Jaya Menggunakan Metode FIFO," J. Intra Tech, vol. 1, no. 1, pp. 31-42, 2017.

[3] J. Simatupang and S. Sianturi, "PERANCANGAN SISTEM INFORMASI PEMESANAN TIKET BUS PADA PO. HANDOYO BERBASIS ONLINE," J. Intra Tech, vol. 3, no. 2, pp. 11-25, 2019. 
[4] A. Ardian, I. Purnama, and V. Sihombing, "Perancangan Aplikasi Pengolah Data Siswa Berbasis Android (Studi Kasus: Mis Nurul Huda Labuhan Batu Selatan)," Pengabdi. Masy. Ika Bina En Pabolo, vol. 1, no. 1, pp. 40-53, 2019.

[5] G. J. Yanris, "Analisis Dan Implementasi Data Mining Dalam Menganalisa Kendala Akademik Yang Sering Dikeluhkan Mahasiswa AMIK Labuhanbatu (Studi Kasus : Amik Labuhanbatu)," Informatika, vol. 4, no. 1, pp. 15-24, 2016.

[6] V. Sihombing, "Aplikasi Simade (Sistem Informasi Manajemen Desa) Dalam Meningkatkan Pelayanan Administrasi di Kepenghuluan Bakti Makmur Kecamatan Bagan Sinembah Kab. Rokan Hilir Riau," SISTEMASI, vol. 7, no. September, pp. 292-297, 2018.

[7] V. Sihombing, "Sistem Informasi Penjualan Mobil Suzuki Di Dealer Bagan Batu," SISTEMASI, vol. 7, no. 2, pp. 113119, 2018.

[8] W. Purba, S. Aisyah, and S. P. Tamba, "Perancangan Sistem Pakar Diagnosa Penyakit Mata Katarak Menggunakan Konsep Metode Runut Mundur," JUSIKOM PRIMA (Junal Sist. Inf. Ilmu Komput. Prima), vol. 1, no. 1, 2017.

[9] V. M. Siregar and H. Sugara, "Perancangan Dan Implementasi Aplikasi Penggajian Berbasis Dekstop Pada Murni Sadar English Course," J. Tek. Inf. dan Komput., vol. 1, no. 2, pp. 42-48, 2018.

[10] V. M. M. Siregar, "Sistem Informasi Pembelian Dan Penjualan Pakaian Pada Galoenk Distro Pematangsiantar," JurTI (Jurnal Teknol. Informasi), vol. 1, no. 2, pp. 219-227, 2017.

[11] V. M. M. Siregar, "Sistem Informasi Pendataan Logistik Aktiva Tetap PT. Bank Central Asia, Tbk Kantor Cabang Pematangsiantar," SISTEMASI, vol. 7, no. September, pp. 250-258, 2018.

[12] V. M. Siregar, H. Sugara, and G. A. Purba, "APLIKASI PENCATATAN LAPORAN PENJUALAN KITA-KITA. NET BERBASIS WEB," J. Tek. Inf. dan Komput., vol. 2, no. 1, pp. 80-86, 2019.

[13] V. M. M. Siregar, H. Sugara, and I. M.
Siregar, "Perancangan Sistem Informasi Pendataan Barang Pada PT. Serdang Hulu," J. Comput. Bisnis, vol. 12, no. 2, pp. 111-117, 2018.

[14] H. A. Simbolon and V. M. M. Siregar, "Perancangan Sistem Informasi Berbasis E-Commerce Untuk Peningkatan Penjualan Produk Jersey Olah Raga," $J$. Tek. Inf. dan Komput., vol. 1, no. 2, pp. 49-54, 2018.

[15] V. M. M. Siregar, "Perancangan Sistem Informasi Inventaris Barang Pada Sekolah SMA Negeri 4 Pematangsiantar," IT J. Res. Dev., vol. 3, no. 1, pp. 54-61, 2018.

[16] M. R. Aryanti, Purwanto, and Suharyadi, "Perancangan Sistem Informasi Akuntansi Penerimaan Kas (Studi Kasus : Koperasi Kota Salatiga)," @is Best Account. Inf. Syst. Inf. Technol. Bus. Enterp., vol. 04, no. 2019, pp. 121-135, 2020.

[17] S. Fauziah, "Perancangan Aplikasi Sistem Informasi Pembelian Dan Penjualan Alat Tulis Kantor," J. Mantik Penusa, vol. 3, no. 3, pp. 61-68, 2019. 